\title{
Educational audit on drug dose calculation learning in a Tanzanian school of nursing
}

\author{
Angela Ruth Savage
}

St John's University of Tanzania

\begin{abstract}
Background: Patient safety is a key concern for nurses; ability to calculate drug doses correctly is an essential skill to prevent and reduce medication errors. Literature suggests that nurses' drug calculation skills should be monitored.

Objective: The aim of the study was to conduct an educational audit on drug dose calculation learning in a Tanzanian school of nursing. Specific objectives were to assess learning from targeted teaching, to identify problem areas in performance and to identify ways in which these problem areas might be addressed.

Methods: A total of 268 registered nurses and nursing students in two year groups of a nursing degree programme were the subjects for the audit; they were given a pretest, then four hours of teaching, a post-test after two weeks and a second post-test after eight weeks.

Results: There was a statistically significant improvement in correct answers in the first post-test, but none between the first and second post-tests. Particular problems with drug calculations were identified by the nurses / students, and the teacher; these identified problems were not congruent.

Conclusion: Further studies in different settings using different methods of teaching, planned continuing education for all qualified nurses, and appropriate pass marks for students in critical skills are recommended.
\end{abstract}

Keywords: Drug calculation, nurse, student nurse, mathematics, audit

DOI: http://dx.doi.org/10.4314/ahs.v15i2.44

\section{Introduction}

Health workers must "above all, do no harm"; safety considerations are paramount in drug administration. Medication errors can be the result of various factors including illegibly written prescriptions, and errors in dispensing, calculation, monitoring, and administration (such as giving the drug to the wrong patient $)^{1}$. Medication errors may have serious, even fatal implications ${ }^{2}$, as well as jeopardise a health worker's career. Error rates as high as one in ten medication administrations have been reported in England and Wales by the national patient safety agency ${ }^{3}$. One of the component skills in drug administration is that of drug dose calculation; nurses and other health workers involved need to calculate doses with complete accuracy.

\section{Corresponding author:}

Angela Ruth Savage

St John's University of Tanzania

P O Box 47, Dodoma

Phone number: +255 787744414

Email address: asavage@sjut.ac.tz
Nurse educators must ensure that all students who qualify to become practising nurses are competent in drug calculation, as well as to audit the teaching / learning activities that they are involved in. Practising nurses need periodic evaluated continuing education to ensure that they remain competent in key skills such as drug calculation.

The aim of the study was to conduct an educational audit on drug dose calculation learning in a Tanzanian school of nursing. Specific objectives were to assess learning from targeted teaching, to identify problem areas in performance and to identify ways in which these problem areas might be addressed.

\section{Materials and methods}

The researcher formulated ten questions based on the national curriculum requirements and the author's 10 years of Tanzanian clinical teaching experience of what is relevant and important for safe clinical practice in Tanzania. While beginning teaching this section of the course, these 10 questions were administered as a pretest. One of these related to number of units, two to volume, one to insulin volume, two to dilution of solutions, three to infusion rates and one to paediatric dose 
calculation. An example of this set of 10 questions is figures were used between the pre and post-test to enshown in table 1 . Every test that was administered fol- sure that nurses/students carried out calculations rathe lowed the exact format of the pretest. Slightly different than reproducing remembered answers, without making the test more or less difficult.

\section{Table 1. Example of questions used as pretest and post-test}

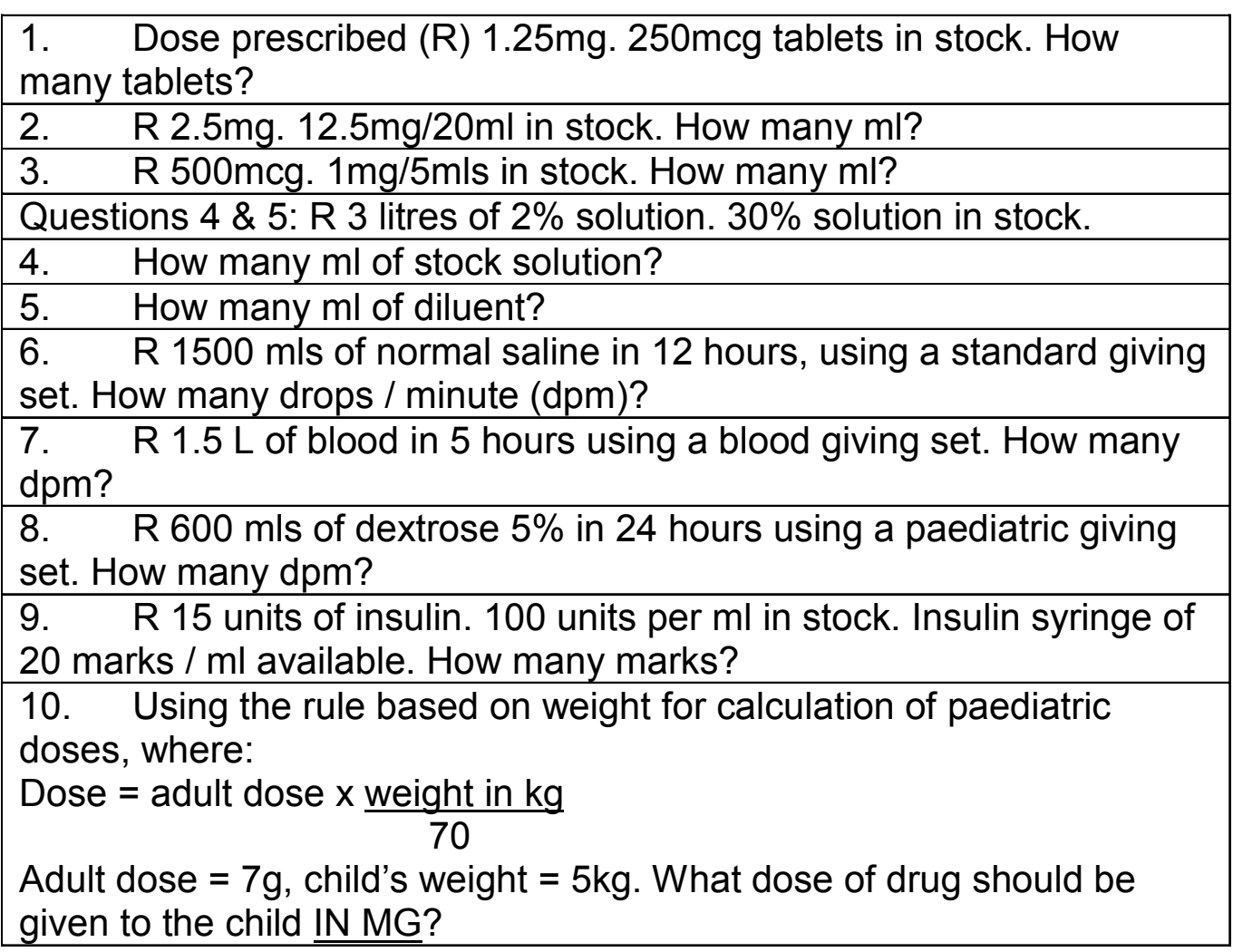

After the pretest, four hours were used in classroom and then returned to students within one week. The teaching of the subject matter, covering all the issues in nurses were also advised to expect 10 similar questions the pretest. The method used for calculations was the in a subsequent test eight weeks later.

formula method, as this was congruent with the meth-

od used in registered nursing programmes. This meth- This process was carried out in the second year of studod was used within the context of the 3-step approach ies of a nursing degree programme in two consecutive of "convert, compute, critically think" that stresses the years, 2011-2012 (second semester) and 2012-2013 need to ensure that the same units of measurement are (first semester). The total number of participants was being used (convert), and checking that the answer is 268. The first group was 178 registered nurses and the "sensible" (critically think) ${ }^{4}$. This teaching involved second group was 64 registered nurses. The registered providing formulae, showing worked examples step by nurses had all previously completed a four year prostep and allowing time for the students/nurses to prac- gramme which included calculations in pharmacology, tise other examples, until all of them reported that they and all had had post-registration experience prior to did not need any more practice examples. The nurses/ joining the degree programme. Entry to registered nursstudents were advised to review the handouts provided, ing programmes is after form four ('O' level equivalent). practise examples and prepare for a post-test using the A group of 26 nursing students direct from school who same format as the pretest, but with different figures, were taught at the same time as the second group of two weeks later. Pretests were marked and returned to registered nurses were also tested. This group had not students. The post-test papers were collected, marked had any clinical practice experience, but had undergone
Students were identified using registration number only: no names or other identifiers were used. Data was stored in a computer to which no-one else had access.

Twenty minutes were allowed for the testing. Calculators were allowed, although all of the calculations could have been managed without a calculator.

The potential sample size was 334 participants, but the 66 nurses/students who were absent on any one of the three occasions were excluded from the analysis.

Results for each question for each individual nurse were recorded in an excel spread sheet. One mark was awarded for a correct answer; zero for an incorrect answer. Exactly correct answers were awarded a mark, with a margin of error of plus or minus two only allowed for intravenous fluid drop rates. No half marks were given. The scores for each item and overall scores were computed and compared between the three testing occasions and results from the three groups compared.

At the end of the course, the first group of nurses were requested to complete a course evaluation form which had a section in which to indicate which of nine problems they identified as personal calculation problems. Of the total of 229 nurses in this group, who were all given this form and requested to complete it, only 60 did so, of these 30 completed the section of the evaluation form on calculation problems. It is not known if these were representative of the group. The results of this self-evaluation were analysed.

The proposal for this audit was presented to the University ethics committee, who advised that as an educational audit, ethical approval was not required until the report was prepared for publication. The report was submitted to the ethics committee for review and was approved prior to submission for publication.
An educational audit is an essential part of monitoring the quality of teaching/learning activities. It is a required aspect of professional practice, and is required by the university authorities and those that govern tertiary education in Tanzania. It benefits the student by checking that activities have met the intended goals; it helps the teacher to identify student or teacher problems and thereby rectify them. It benefits the institution by providing a measure of quality that can help to establish its credibility.

This activity, by raising students' awareness of its importance by the use of a pre-test and two post-tests, may have encouraged students to work hard and thereby improve their competence in this skill. If there was improved competence as a result of the extra effort, this could result in reduced risk of drug dose error in any patients that they subsequently attend to, and would improve their ability to teach and supervise others accurately.There was no loss of time on the part of the students involved, as the activities were a normal part of their learning activities.

\section{Results}

The percentage of students scoring correctly per question was calculated by adding the number of correct scores for each question and converting this into a percentage for each of the three groups: group 1 (registered nurses), $\mathrm{n}=178$, group 2 (registered nurses), $\mathrm{n}=$ 64 and group 3 (direct entrants from school), $n=26$.

The pretest scores showed heterogeneity of scores per different question types and some variability between groups of students, as shown in figure 1. The second and third tests showed a relative homogeneity of scores per question type and between student groups; figure 2 shows results of the second testing occasion. 

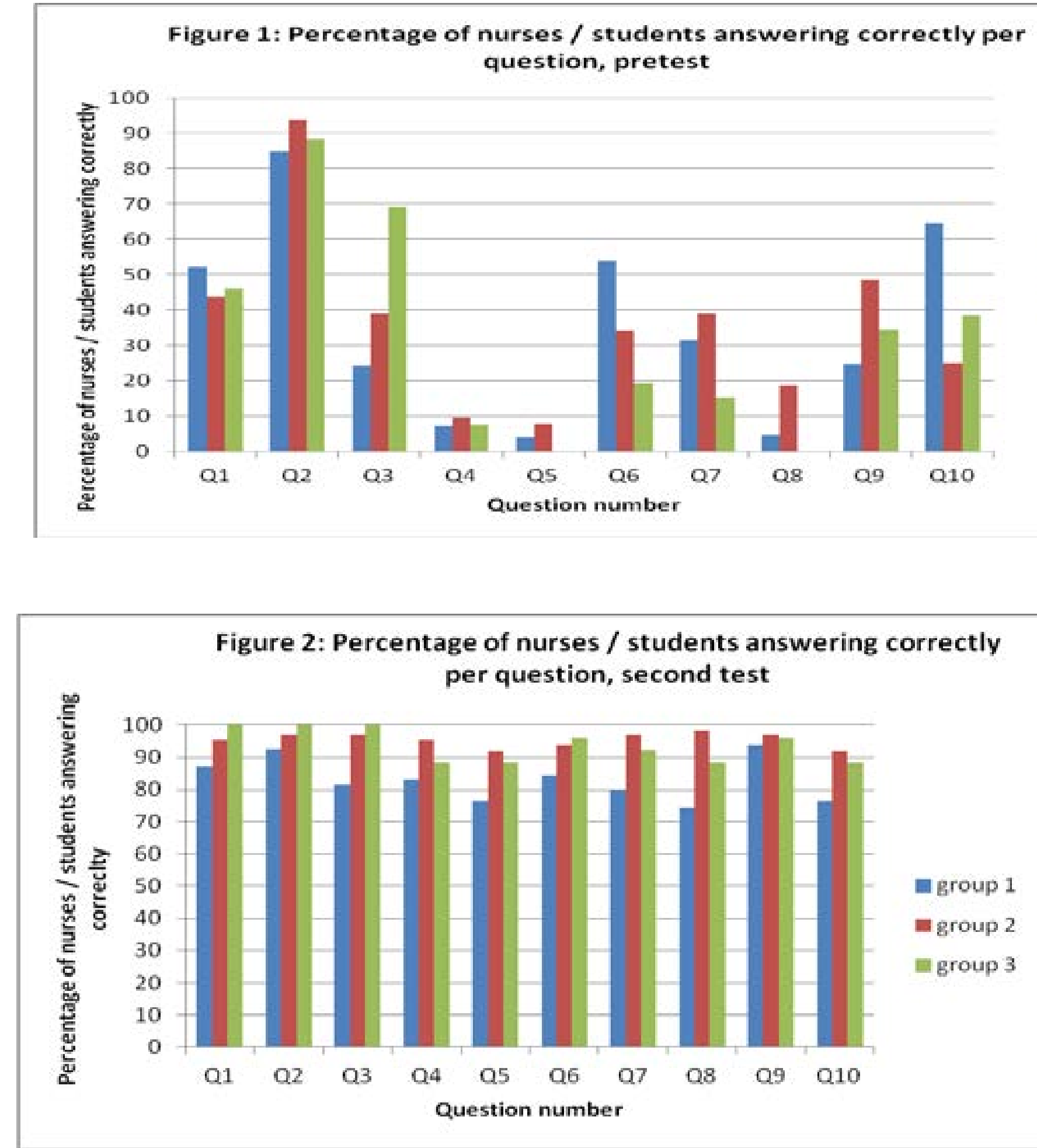

The average percentage scores per group and total sam- tests. Standard deviations varied between groups and ple are shown in table 2, where it can be seen that there testing occasions, but were lowest in group 3 (direct enare small differences between the three groups at the trants from school) on the second post-test. The ranges pretest, that all groups improved markedly between the also varied between groups and testing occasions, with pretest and the first post-test and that there were very the smallest ranges found in groups 2 and 3 at post-test small differences between the first and second post- 1 .
Table 2: Average percentage scores per group and total sample, score standard deviations (SD) and score ranges per group

\begin{tabular}{|l|l|l|l|}
\hline & \multicolumn{4}{|l|}{ Average percentage score } \\
\hline Group & Pretest & Post-test 1 & Post-test 2 \\
\hline Group 1 $(\mathrm{n}=178)$ & $35(\mathrm{SD}=1.70)$ & $83(\mathrm{SD}=1.97)$ & $85(\mathrm{SD}=1.61)$ \\
& $($ Range=0-9) & $($ Range=2-10) & $($ Range=2-10) \\
\hline Group 2 $(\mathrm{n}=64)$ & $27(\mathrm{SD}=1.25)$ & $95(\mathrm{SD}=0.85)$ & $91(\mathrm{SD}=1.30)$ \\
& $($ Range=0-6) & $($ Range=7-10) & $($ Range=4-10) \\
\hline Group 3 $(\mathrm{n}=26)$ & $32(\mathrm{SD}=1.39)$ & $94(\mathrm{SD}=1.02)$ & $93(\mathrm{SD}=0.40)$ \\
& $($ Range $=1-5)$ & $($ Range=7-10) & $($ Range=6-10) \\
\hline Total sample $(\mathrm{n}=$ & 33 & 87 & 89 \\
268) & & & \\
\hline
\end{tabular}

The data was analysed using dependent t-tests, and When marking the tests, it was noted that the majority showed a statistically significant improvement between of errors were those of calculation; largely multiplicathe pretest means of 35, 27 and 32 and the second test tion and division. This impression was supported by the means of 83,95 and $94(t=9.9291, \mathrm{df}=2, \mathrm{p}=0.0100)$. poor results relating to pretest question 10 , in which a There was no statistically significant difference between formula was provided. A sample of 20 post-test papers the second test means of 83, 95 and 94 and the third (each with 10 questions, that is 200 questions in total) in test means of 85,91 and $93(\mathrm{t}=0.5774, \mathrm{df}=2, \mathrm{p}=$ which "working out" was shown were taken randomly $0.6220)$. from the first group and analysed, as shown in figure 3 . Some test papers had unnecessarily long and complicated answers.

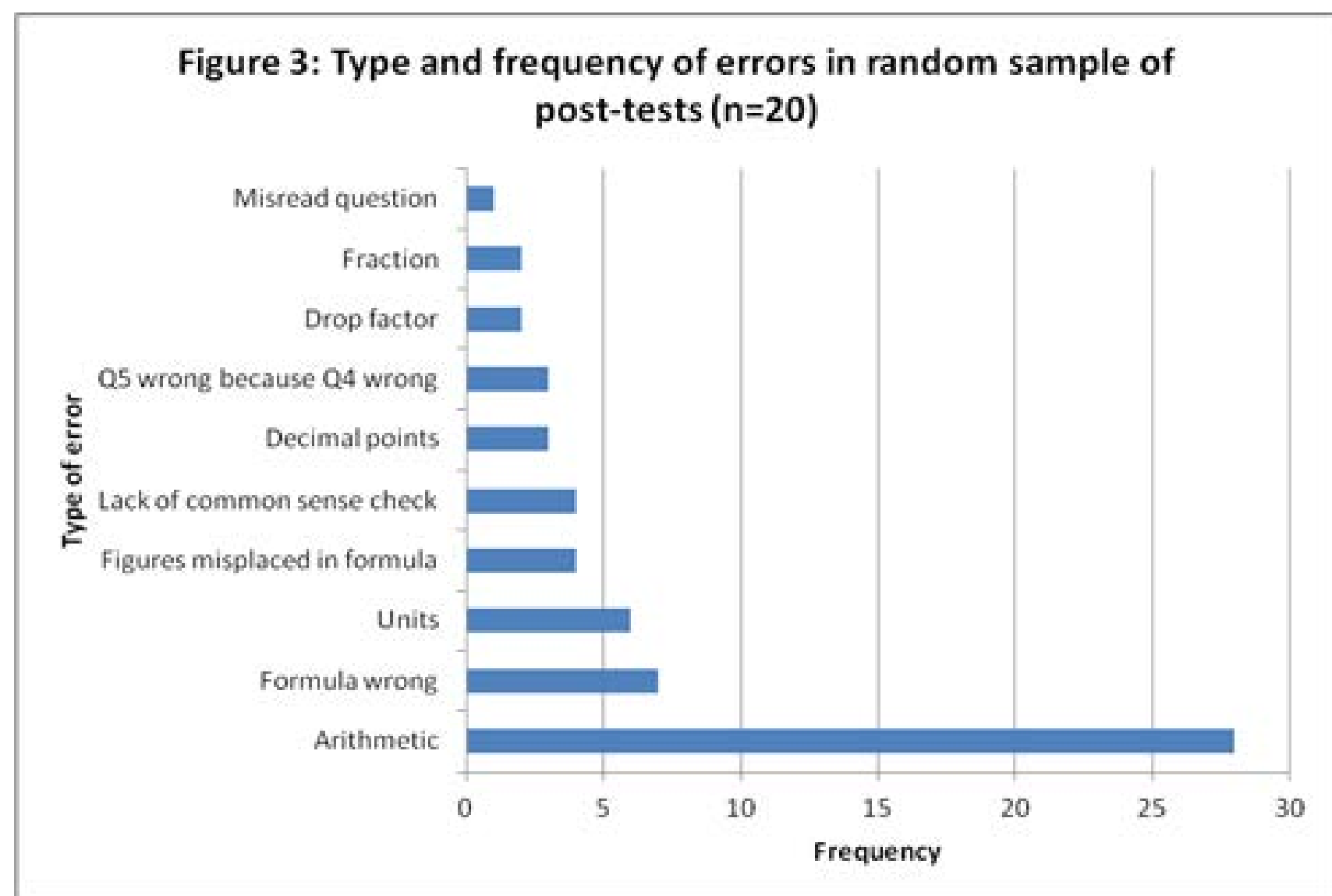


Figure 4 shows self-identified problems of 30 group 1 gruent, particularly in respect to the different extent of nurses. The teacher identified and nurse/student identi- identification of arithmetic errors. The teacher found fied problems presented in figures 3 and 4 are not con- this to be a more common problem than nurses/students perceived this to be.

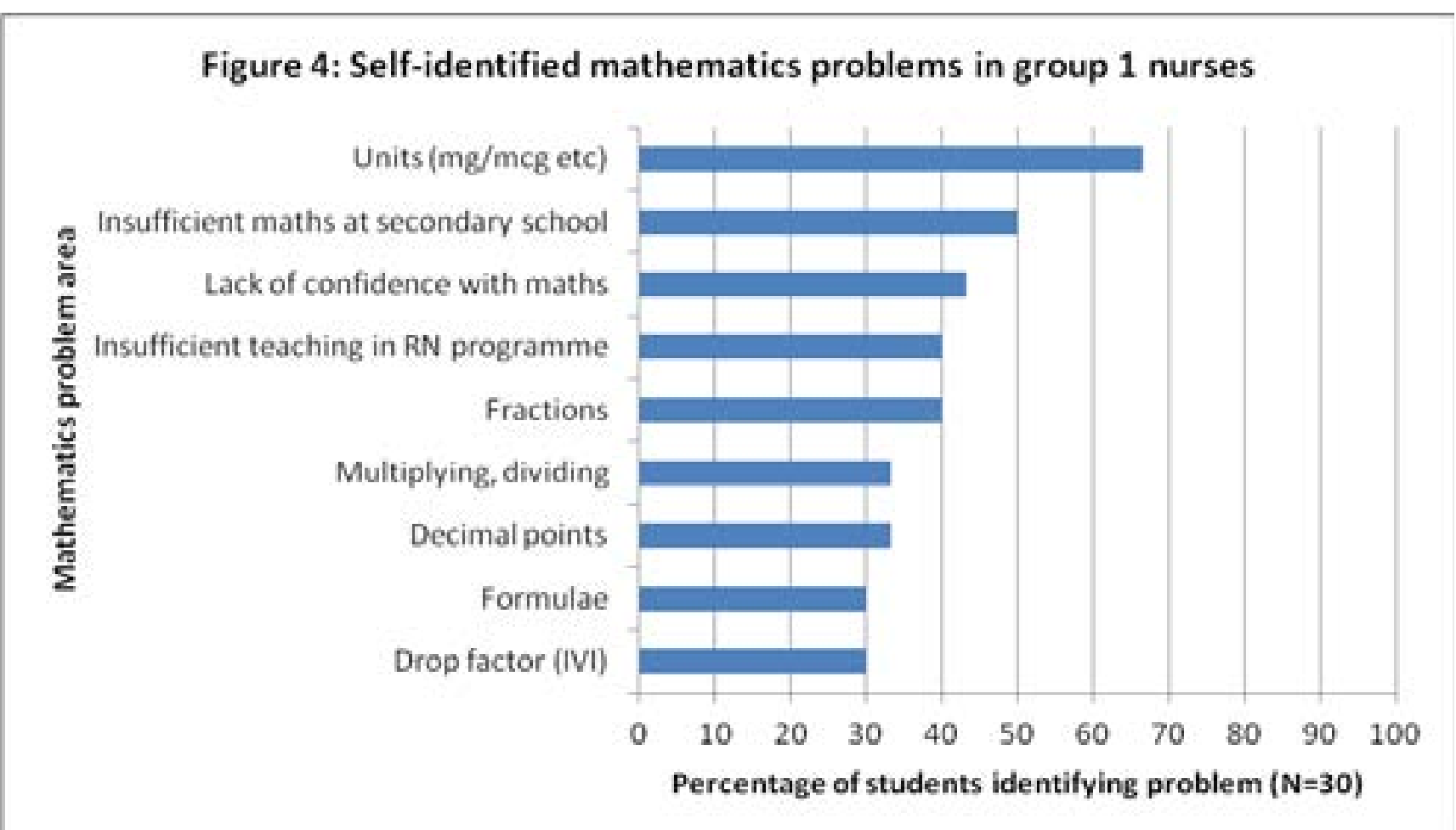

Other problem areas that were self-identified by one Three studies in the United States of America on medstudent each in an open-ended section of the end of course evaluation were as follows:

- Insulin calculation

- Learning a different method with a previous instructor

- Dilution of solutions

- More practice needed

- Insufficient time for calculations

\section{Discussion}

The targeted teaching audited in this study was effective as judged by the statistically significant improvement in scores between the pre-test and post-test. The reasons for this improvement may have included that students were motivated by this learning activity being part of compulsory recorded evaluations. A less significant improvement was noted in Botswana with 13 pupil nurs$\mathrm{es}^{5}$ where the post-test results were not used as a part of formal student evaluations, and in United Kingdom with 184 student nurses ${ }^{6}$ in which self-instructional material rather than teacher-student interactive session were used. and in the UK. $14,15,16,17,18$ This suggests that Tanzanian students/nurses are not alone in having problems with mathematical calculations; computational skills, decimal places and ratios are recurring problems identified in this and other studies.

In this study some nurses reported a lack of confidence and lack of mathematics instruction at school. The lack of confidence in mathematics reported by students in this study is congruent with findings in Australia ${ }^{19}$.

A study in Ireland ${ }^{20}$ with a sample of 124 nurses starting employment suggests that nurse education institution are giving a variable amount of emphasis to drug calculation skills. This is congruent with some nurse reports in the current study of insufficient instruction in reoistered nurse training schools on drug calculation. Graduating nurses found that the introductory course of drug calculations was uninteresting and poorly organized, in a Finnish study. ${ }^{21}$

This study found a lack of congruence between self-identified problems and observed problems. Nurses/students appear to underestimate their lack of arithmetic skills compared to the teacher observation. This suggests that objective measures are needed when auditing skills.

Limitations of the study are that this was carried out formally in only one institution, although the author had carried out similar unpublished audits in two other Tanzanian settings with similar results. The results cannot be generalised to a larger population of nurses/ students in Tanzania. Only the formula method of calculation was used, and calculations were only carried out in the classroom setting. Use of other methods and clinical settings (with additional situational clues) might have produced different results. The author conducted the audits alone so checks on reliability were a potential limitation.

Targeted teaching has the potential to be highly effective in increasing classroom test performance; it is probably most effective when students are motivated by tes scores "counting" towards their overall scores. Whether targeted teaching is effective in preventing and reducing medication errors requires further investigation.

The results in this study suggest that the study should be replicated in a variety of settings across Tanzania in order to be able to generalise the findings. Different set- tings and teaching approaches to drug calculation could be tried, such as proportional or dimensional analysis as an alternative to conventional formula based methods used in this study ${ }^{22,23}$

Practice-based learning may be effective, either from the beginning of the learning or revision, 20,24 or as part of a three-stage approach involving teaching of mathematical concepts, teaching drug calculation formulae and then practising these skills in a clinical setting. ${ }^{25}$ It has been argued that " $[t]$ he context is required to make the problem understandable"26.

The homogeneity of average percentage correct responses across the three groups was surprising, since the registered nurses had all had four years nurse education prior to entering the degree programme, while the student nurse group had not had any prior nurse education. It would be appropriate to investigate the quality of nurses' theoretical and practical drug calculation. Where practical ability is lacking, it would be important to ensure that evaluated continuing education programmes are introduced. These should include mandatory checks on drug calculation accuracy as a distinct competency, perhaps biannually. ${ }^{20,27}$

Nurse educators should be active in identifying issues that affect patient safety, involved in monitoring and developing policies and guidelines, and be conversant with the clinical realities so that relevant issues are addressed. Comprehensive total quality management programmes that combine a systems approach with a non-punitive approach to reporting errors would appear to be appropriate in all clinical settings. Preventive strategies that are relevant for the specific setting should be identified. This may involve increasing staff and avoiding distractions when medications are administered. $28,29,30,31,32$

It cannot be assumed that student and qualified nurses have adequate mathematical skills to practise safely. Al student nurses need a foundation mathematics course including basic computations, decimal places and units of measurement. An individual and context-specific analysis is appropriate to identify particular weaknesses, followed by individualised remedial activities. Computer aided programmes and e-learning packages would allow students to progress at their own speed and practice particular sections until mastery is reached..$^{33}$ 
If the findings of this study are found to be represent- ogy for health careers (6th ed). Boston: McGraw Hill; ative of the nursing population of Tanzania, the identi- 2009

fied weaknesses in calculation would suggest that pass- 3. Jones SW. Reducing medication administration error ing a basic mathematics course should be an essential in nursing practice. Nurs Stand. 2009;23(50):40-46. prerequisite to the pharmacology course. A preparato- 4. Boundy JF, Stockert PA. Calculation of medication ry course may increase confidence and competence in dosages. Philadelphia: Wolters Kluwer Lippincott Wilmedication calculation. ${ }^{3}$ liams \& Wilkins; 2008.

5. Savage A. IV drugs: assessing pupils in Botswana. Quality secondary school mathematics programmes are Nurs Stand. 1992;6(35):29-32.

important for potential nurses. Tanzania currently has 6. Hutton BM. Nursing mathematics: the importance a shortage of science and mathematics teachers, which of application. Nurs Stand. 1998;13(11):35-38. the relevant authorities are trying to address.

7. Ashby DA. Medication calculation skills of the medical-surgical nurse. Medsurg Nurs. 1997;6(2):90-94.

The quality of the teaching/learning experience in nurs- 8. Harne-Britner S, Kreamer CL, Frownfelter P, Heling drug calculations should be monitored and the pass muth A, Lutter S, Schafer DJ et al. Improving medicacriterion for pharmacology calculation courses should tion calculation skills of practicing nurses and senio be considered in the light of the risks associated with nursing students. J Nurses Staff Dev. 2006;22:190-195.

inaccurate drug calculation. A pass mark of $50 \%$ in this 9. Rainboth L, DeMasi C. Nursing students' mathematskill is inappropriate. An Australian example ${ }^{35}$ could ic calculation skills. Nurse Educ Pract. 2006; 6:347-353. be followed. Student nurses are assessed every year in 10. Kapborg I. Calculation and administration of drug drug calculation skills with a 20 question test. A pass dosage by Swedish nurses, student nurses and physimark of $75 \%$ is accepted in 1st year, 85\% in 2nd year cians. Int J Qual Health Care. 1994;6:389-395.

and $100 \%$ in 3rd year. Students who do not achieve this 11. McMullan M. Exploring the numeracy skills of level are given remedial exercises and explanations, and nurses and students when performing drug calculahave repeated up to three times in order to reach the tions. Nurs Times. 2010;106(34):10-12.

pass mark. An evaluation in the clinical setting should 12. Blais K. Bath J. Drug calculation errors of baccalaualso be mandatory for every student nurse.

The use of calculators in learning and practice situations should be investigated in Tanzania; while the use of calculators may reduce calculation errors, they do not reduce conceptual errors, such as a student suggesting that a patient be given an $18 \mathrm{ml}$ intramuscular injection. ${ }^{35}$

Further audits using alternative methods and setting are recommended. Student and regular in-service testing should use pass marks that promote safe practice. reate nursing students. Nurse Educ.1992;17(1):12-15. 13. Grandell Niemi H, Hupli M, Leino Kilpi H. Medication calculation skills of nurses in Finland. J Clin Nurs 2003;12:519-528.

14. Barrett G. Which calculations do child branch student nurses find most difficult in the classroom setting? I Child Young People Nurs. 2007;1:112-118.

15. Hutton M. Calculations for new prescribers. Nurs Stand. 2003;17(25):47-52.

16. Jukes L, Gilchrist M. Concerns about numeracy skills of nursing students. Nurse Educ Pract. 2006; 6:192-198.

17. Lapham R, Agar H. Drug calculations for nurses. No financial support received for this study from any A step by step approach (3rd ed). London: Hodder Arsource

\section{Declaration of conflicts of interest:} nold; 2009.

18. Wright K. Barriers to accurate drug calculations Nurs Stand. 2006;20(28):41-45.

The author has no vested interest in any of the out- 19 . Glaister $\mathrm{K}$. The presence of mathematics and comcomes of this audit: no conflicts of interest exist.

\section{References}

1. Mayo AM, Duncan D. Nurse Perceptions of Medication Errors: What We Need to Know for Patient Safety. J Nurs Care Qual. 2004;19(3):209-217. medication dosage calculations. Nurse Educ Today. 2007;27(4):341-347.

20. Fleming S, Brady A, Malone A. An evaluation of the drug calculation skills of registered nurses. Nurse Educ Pract. 2013;30:1-7.

2. Gauwitz DF. Administering medications. Pharmacol- 21. Grandell-Neimi H, Hupli M, Leino-Kilpi H. Med- ication calculation skills of graduating nursing students in Finland. Adv Health Sci Educ Theory Pract. 2001;6:15-24.

22. Kohtz C, Gowda C. Teaching Drug Calculation in Nursing Education, A Comparison Study. Nurse Educ. 2010;35(2):83-86.

23. Wright K. Drug calculations part 2: alternative strategies to the formula. Nurs Stand. 2008;22(37):42-44.

24. Wilson A. Nurses' maths: researching a practical approach. Nurs Stand. 2003;17(47):33-36.

25. Wright K. An exploration into the most effective way to teach drug calculation skills to nursing students. Nurse Educ Today. 2005;25:430-436.

26. Wright K. Drug calculations part 1: a critique of the formula used by nurses. Nurs Stand. 2008;22(36):40-42 27. Axe S. Numeracy and nurse prescribing: Do the standards achieve their aim? Nurse Educ Pract. 2011;11:285-287.

28. Burdeu G, Crawford R, van de Vreede M, McCan J. Taking Aim at Infusion Confusion. J Nurs Care Qual. 2006;21(2):151-159.
29. Jones SW. Reducing medication administration erors in nursing practice. Nurs Stand. 2009;23(50):40-46. 30. Montesi G, Lechi, A. Prevention of medication errors: detection and audit. Br J Clin Pharmacol. 2009; 67(6):651-655.

31. Petrova E, Baldacchino D, Camilleri M. Nurses perceptions of medication errors in Malta. Nurs Stand. 2010;24(33):41-48.

32. Warburton P. Numeracy and patient safety: the need for regular staff assessment. Nurs Stand. 2010;24(27):42-44.

33. McQueen DS, Begg MJ, Maxwell SJR. eDrugCalc: an online self-assessment package to enhance medical students' drug dose calculation skills. Br J Clin Pharmacol. 2010; 70(4):492-499.

34. Chapman L, Halley L. Numeracy skills: a student-centred approach to gaining confidence. Nurs Prescr. 2007;5(4):157-160

35. Elliott M, Joyce J. Mapping drug calculation skills in an undergraduate nursing curriculum. Nurse Educ Pract. 2005;5(4):225-229. 